\title{
Pengembangan Sistem Informasi Absensi Karyawan Menggunakan Barcode Pada PT. Primayudha Mandirijaya
}

\author{
Agung Tri Utomo* ${ }^{1}$, Suprihadi ${ }^{2}$ \\ ${ }^{1,2}$ Universitas Kristen Satya Wacana; Jl. Diponegoro 52-60, Salatiga, Kec. Sidorejo, Kota \\ Salatiga, Jawa Tengah, 50711, (0298)321212 \\ ${ }^{3}$ Jurusan Teknik Informatika, FTI UKSW, Salatiga \\ e-mail:*1672017203@ @student.uksw.edu, ${ }^{2)}$ suprihadi@uksw.edu
}

\begin{abstract}
Abstrak
PT Primayudha Mandirijaya merupakan salah satu perusahaan yang bergerak dalam pemintalan kapas menjadi benang, perusahaan memiliki karyawan yang cukup banyak dalam hal ini perlunya memanajemen absensi yang tepat cepat dan akurat, penelitian ini membahas tentang perancangan sistem absensi web dengan menggunakan barcode karena dalam hal ini masih adanya absensi yang dilakukan manual tentu akan merepotkan dalam pengarsipan data karyawan. Sistem dibuat menggunakan bahasa pemrograman PHP dengan menggunakan database mysql sebagai tempat untuk menyimpan data karyawan. Framework vue js juga digunakan untuk mempercantik tampilan dalam sistem absensi. Barcode menjadi salah satu pemanfaatan teknologi yang bisa memudahkan dalam penggunaanya. Sistem sudah di uji menggunakan UAT dengan memperoleh 71,3\% dengan keterangan setuju.
\end{abstract}

Kata kunci-Barcode, Absensi, Vue js, Web, SDLC.

\begin{abstract}
PT Primayudha Mandirijaya is one of the companies engaged in spinning cotton into yarn, the company has quite a lot of employees, in this case the need for proper attendance management, fast and accurate, this study discusses the design of a web attendance system using barcodes because in this case there is still attendance which is done manually will certainly be a hassle in filing employee data. The system is created using the PHP programming language using the MySQL database as a place to store employee data. The vue js framework is also used to enhance the appearance of the attendance system. barcode is one of the technology users that can make it easier to use. The system has been tested using UAT by obtaining $71.3 \%$ with a statement agreeing.
\end{abstract}

Keywords-Barcode, Attendance, Vue js, Web, SDLC. 


\section{PENDAHULUAN}

$\mathrm{A}$ bsensi adalah sebuah kegiatan pengambilan data berguna untuk menghitung jumlah kehadiran, dengan berkembangnya teknologi informasi yang sangat pesat absensi yang berjalan di perusahaan masih adanya cara manual tentunya memiliki kekurangan seperti data yang tidak valid ketika data yang masuk salah. Kekurangan lain dari pengambilan data secara manual adalah kurangnya efisien dan efektifitas pada pengolahan data dan juga bisa hilangnya atau rusaknya data yang ada. perkembangan teknologi yang sangat pesat, sehingga manusia dalam mengerjakan setiap pekerjaan selalu membutuhkan komputer. Komputer memiliki peran yang sangat vital dalam pemecahan masalah khusus dalam pengolahan data, karena komputer memiliki kecepatan tingkat akurasi yang tinggi dalam pemrosesan data, sehingga dapat mempermudah pekerjaan manusia. Adanya sistem komputer sangat membantu dalam pemecahan masalah terutama dalam pengolahan data. Penggunaan komputer juga dapat dijadikan alat untuk mencapai tujuan dan mencari kemudahan dalam melakukan sesuatu proses pekerjaan, terutama yang melibatkan banyak data. Perusahaan Primayudha Mandirijaya merupakan salah satu perusahaan yang bergerak dalam hal pemintalan kapas menjadi benang maka perlunya melakukan manajemen pengolahan data yang baik, cepat dan efisien. Prosedur absensi yang diterapkan perusahaan masih adanya absensi yang dilakukan manual tulis kertas. Dengan adanya proses absensi yang di lakukan manual mulai dari pendataan dan perhitungan jam hadir, jam keluar hal ini berdampak pada waktu yang relatif lama dalam proses perhitungan. rekapitulasi absensi dari karyawan dan juga bentuk laporan berupa hardcopy yang dapat menyebabkan kesalahan dalam pencatatan data menyulitkan dalam proses pencarian data dan dikhawatirkan terjadi kehilangan data absensi karyawan.

PT Primayudha mandirijaya memiliki karyawan yang cukup banyak dalam hal ini untuk mengatur manajemen waktu absensi karyawan masih adanya manual sehingga merepotkan pihak dari personalia dalam pendataan karyawan dan juga memperlambat karyawan dalam melakukan absensi apalagi dalam situasi pandemi covid-19 ini. Maka solusi yang diberikan untuk mengatasi masalah tersebut adalah merancang absensi berbasis web dengan memanfaatkan barcode. Sistem menggunakan bahasa pemrograman PHP dengan framework vue.js alasan menggunakan vue.js adalah salah satu framework yang ringan dan modern, menggunakan mysql sebagai database. Dalam era globalisasi sekarang ini, teknologi informasi melaju dengan cepatnya. sistem absensi yang ada masih dilakukan secara manual, mulai dari absen masuk hingga pembuatan laporan untuk absen, sehingga memungkinkan pada saat proses berlangsung terjadi kesalahan dalam pencatatan. Kurang akuratnya laporan yang dibuat dan keterlambatan dalam pengolahan data yang diperlukan [9]. Alasan barcode yang digunakan adalah karena dengan ini hanya cukup nik karyawan saja yang diperlukan untuk melakukan absensi dengan melalui scan barcode di scanner barcode merupakan solusi yang memanfaatkan teknologi informasi yang mampu mengakomodir proses perekaman data absensi sehingga rekapitulasi dapat dilakukan lebih cepat dan akurat, penerapan absensi menggunakan barcode scanner menjadi solusi pemecahan masalah pengolahan data absensi dan memiliki keunggulan dapat melakukan pengambilan absensi dengan cepat, tepat dan akurat. masih menerapkan absensi secara manual, hal ini menimbulkan kebocoran waktu dan pelanggaran lainnya [10]. Sistem tentunya dibuat untuk memudahkan proses absensi perekapan data akan jauh lebih mudah karena data bisa masuk ke database. Dalam proses data - data karyawan akan jauh lebih aman dan tertata karena data akan masuk dan diproses di database. Selain dijaga satpam saat absensi, di sistem juga sudah dirancang hanya bisa melalui scan barcode saja tidak bisa diketik manual di dalam sistem saat melakukan absensi. absensi merupakan hal yang sangat terpenting bagi suatu perusahaan, karena absensi merupakan salah satu hal yang dapat mempengaruhi besar gaji atau upah seorang karyawan. Pelaksanaan proses absensi sangat dibutuhkan ketelitian 
supaya tidak menghambat pekerjaan perusahaan dan dapat menghasilkan laporan absensi yang benar [7].

Berdasarkan latar belakang yang telah dijelaskan maka dapat dirumuskan masalah yaitu bagaimana perancangan sistem absensi menggunakan barcode yang dapat memberikan kemudahan untuk karyawan dalam melakukan absensi. Batasan - batasan dalam pembuatan sistem diantaranya, hanya karyawan yang mempunyai nik yang bisa absensi dan juga dalam pembagiannya dikatagorikan dengan karyawan yang boleh absen sistem tidak bisa di ketik manual oleh karyawan saat melakukan absensi. Dalam pembangunan sistem ini menggunakan bahasa pemrograman PHP dengan code editor Vscode dan juga dalam penyimpanan data menggunakan database mysql. sistem di rancangan dengan framework vue.js.

\section{METODE PENELITIAN}

Penelitian yang dilakukan menggunakan lima tahapan penelitian sebagai berikut pertama analisis kebutuhan dan pengumpulan data, kedua perancangan sistem, ketiga perancangan aplikasi, keempat implementasi dan pengujian sistem, kelima penulisan laporan penelitian. dalam tahap pertama analisis kebutuhan dan pengumpulan data dalam hal ini melakukan wawancara secara langsung kepada staff MIS untuk mengetahui bagaimana alur sistem yang nantinya akan di rancang dan melakukan wawancara terkait apa saja kebutuhan pengguna, dalam tahap kedua merancang sistem dengan menggunakan metode SDLC waterfall. Tahap ketiga perancangan aplikasi menggunakan bahasa pemrograman database mysql dan menggunakan framework vue js. Tahap keempat implementasi dan pengujian sistem yang akan dilakukan kepada karyawan untuk menguji sistem berjalan atau tidak dan dalam penelitian ini sistem bisa berjalan mencatat absensi dengan cepat dan data masuk ke database. Tahap kelima penulisan laporan ilmiah dan artikel ilmiah.

Perancangan aplikasi menggunakan metode system development life cycle dengan model proses waterfall. SDLC adalah proses pembuatan dan pengubahan sistem serta model dan metodologi yang digunakan untuk mengembangkan sistem - sistem tersebut. SDLC berarti siklus hidup pengembangan perangkat lunak yang terdiri dari beberapa tahapan - tahapan yang sangat penting dalam keberadaan perangkat lunak yang dilihat dari segi pengembangannya [4]. Waterfall adalah suatu proses pengembangan perangkat lunak berurutan, dimana kemajuan dipandang sebagai terus mengalir ke bawah, dalam pengembangannya memiliki beberapa tahapan yang runtut : requirement (analisis kebutuhan) system design (design sistem), coding, testing, penerapan program pemeliharaan [12]. 


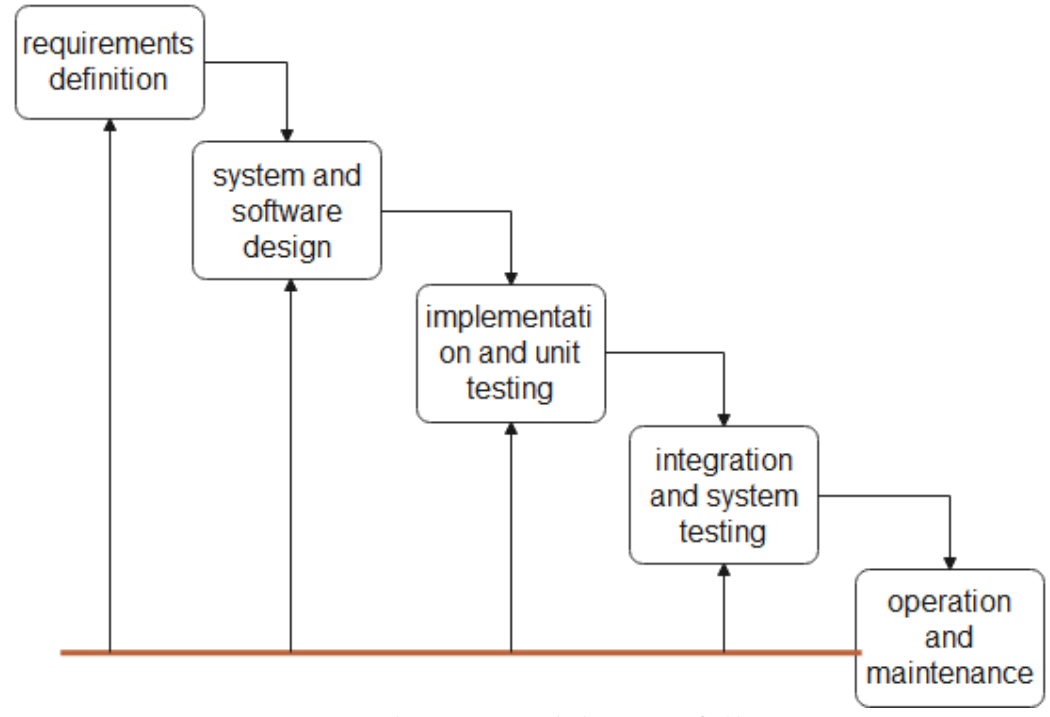

Gambar 1. Model Waterfall

Setelah melihat gambar 1 maka dapat dilanjutkan penulisan tahapan - tahapan pengembangan dalam gambar 1 dijelaskan sebagai berikut: untuk langkah pertama yaitu requirement (analisis kebutuhan) dalam proses analisis ini penulis menemukan suatu masalah yaitu masih terdapat adanya absensi manual, dalam tahap ini melakukan wawancara kepada pihak personalia dan staf MIS untuk mengetahui proses berjalannya absensi dan mengetahui data karyawan. Dalam tahap kedua design System (desain sistem) dalam tahap ini merupakan desain untuk pengembangan sistem. desain terdiri dari desain database dengan menggunakan Xampp dan Mysql sebagai database utama. Tahap ketiga yaitu coding \& testing (penulisan kode program / implementation) pada tahap ketiga adalah coding dimana tahap ini adalah tahap untuk merealisasikan produk yang sudah dirancang sesuai tahap desain. dalam pembangunan sistem menggunakan vscode dan menggunakan bahasa pemrograman php dengan framework vue.js dan Mysql sebagai database. Tahap keempat yaitu penerapan atau pengujian program (integration \& testing) dalam tahap ini untuk memastikan absensi web berbasis web menggunakan barcode berjalan dengan sebagai mestinya, pengujian ini dilakukan dengan tujuan untuk membuat sistem agar tidak mengalami kerusakan saat digunakan oleh pengguna nantinya. Dalam hal ini menggunakan pengujian UAT (user acceptance test). Tahap kelima adalah pemeliharaan (Operation \& Maintenance) perangkat lunak yang susah disampaikan kepada user pasti akan mengalami perubahan. perubahan tersebut bisa karena mengalami kesalahan karena perangkat lunak harus menyesuaikan dengan lingkungan baru, atau karena user membutuhkan perkembangan fungsional.

Unified Modelling Language UML merupakan bahasa visual untuk pemodelan dan komunikasi mengenai sebuah sistem dengan menggunakan diagram dan teks-teks pendukung. UML muncul karena adanya kebutuhan pemodelan visual untuk menspesifikasikan, menggambarkan, membangun dan dokumentasi dari sistem perangkat lunak. pada tahap ini desain arsitektur sistem berisikan tentang perancangan sistem antara lain use case diagram, activity diagram, sequence diagram dan class diagram. Use case diagram absensi web menggunakan barcode terlihat pada gambar 2 . 


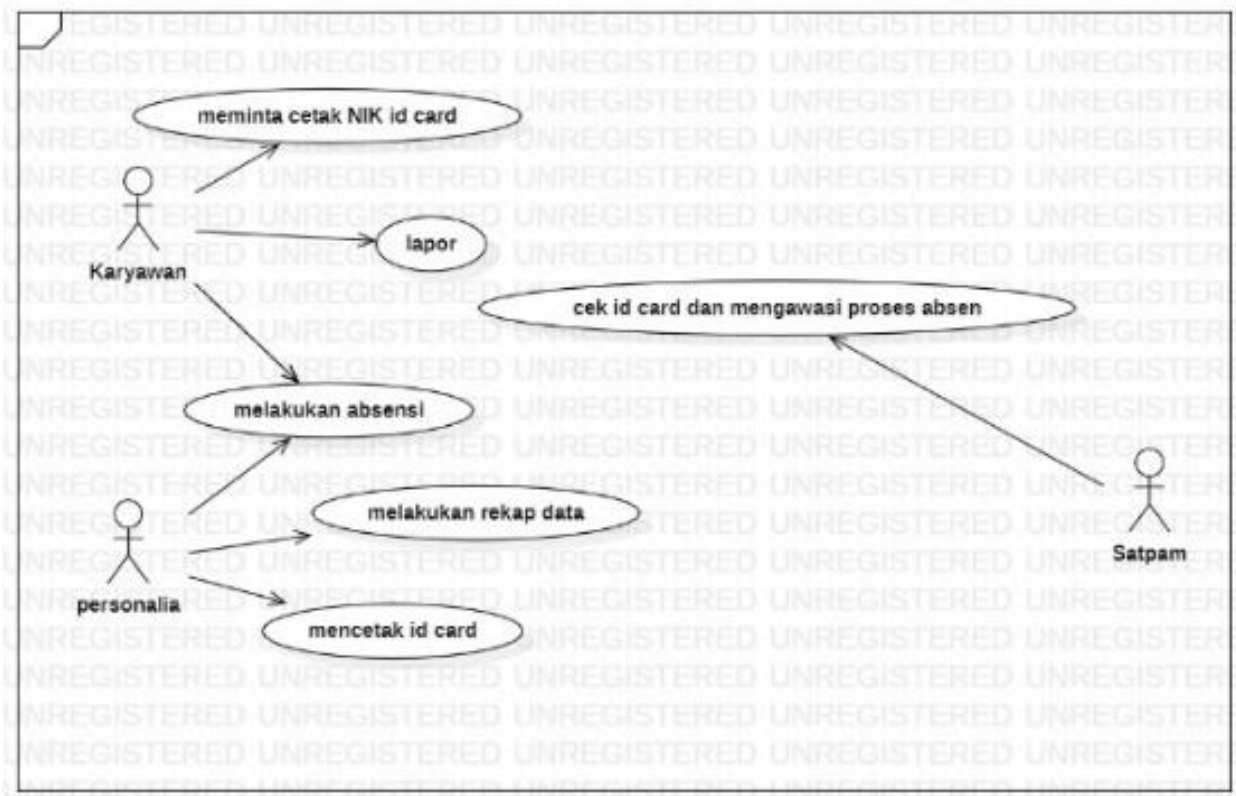

Gambar 2. Use Case Diagram

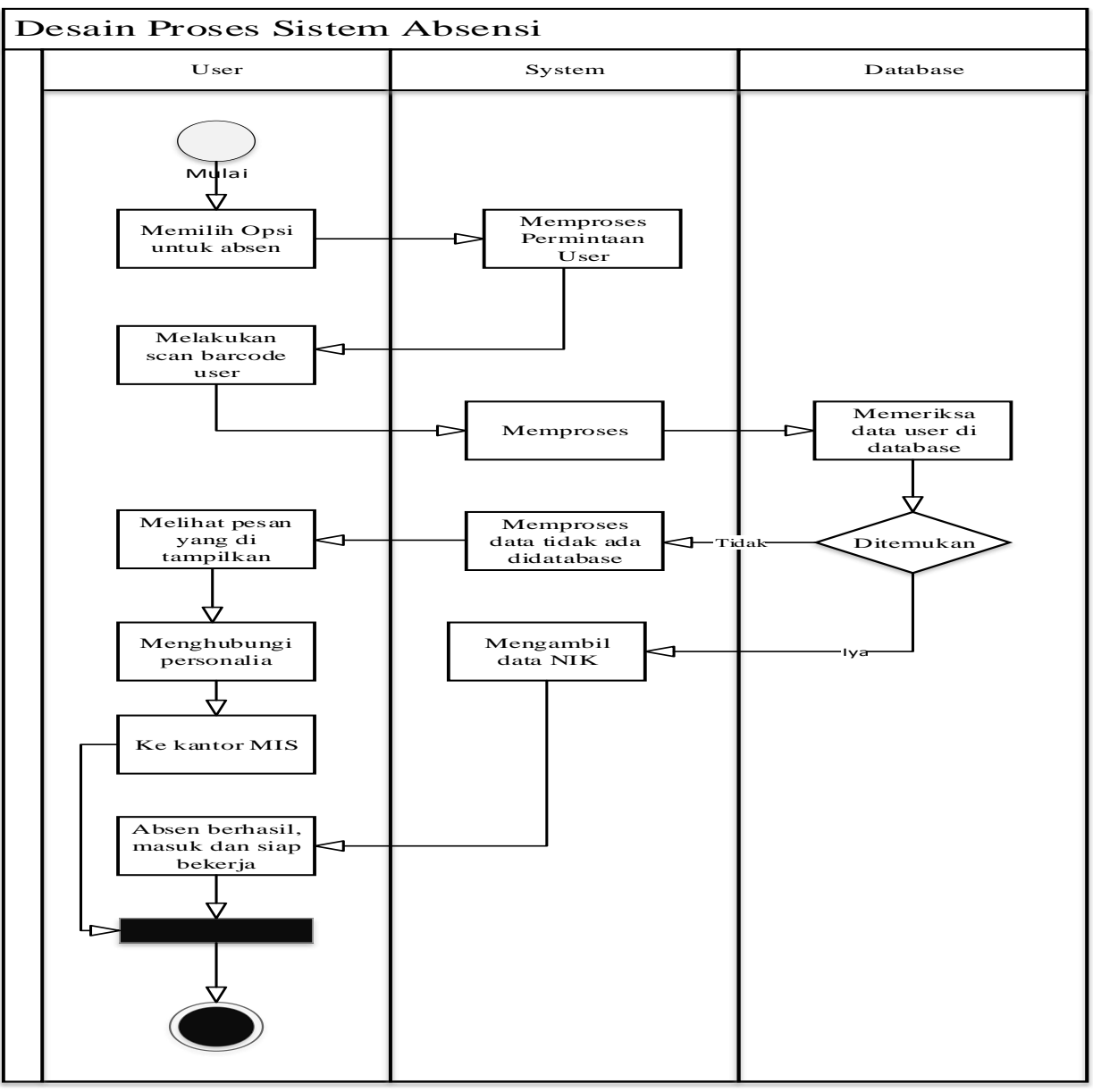

Gambar 3. Activity Diagram Proses Sistem Absensi 
Gambar 3 menjelaskan proses desain sistem dengan menggunakan activity diagram, absensi secara keseluruhan dimulai dengan satpam memilih opsi absensi di sistem kemudian mengecek dan mengawasi proses absensi, sistem memproses permintaan user setelah selesai karyawan melakukan absensi dengan scan barcode, setelah selesai jika data karyawan ditemukan absensi berhasil jika tidak bisa maka nanti akan muncul pesan yang ditampilkan oleh sistem kemudian karyawan menghubungi personalia setelah berkoordinasi dengan personalia kemudian ke kantor MIS proses pembetulan masalah data error.

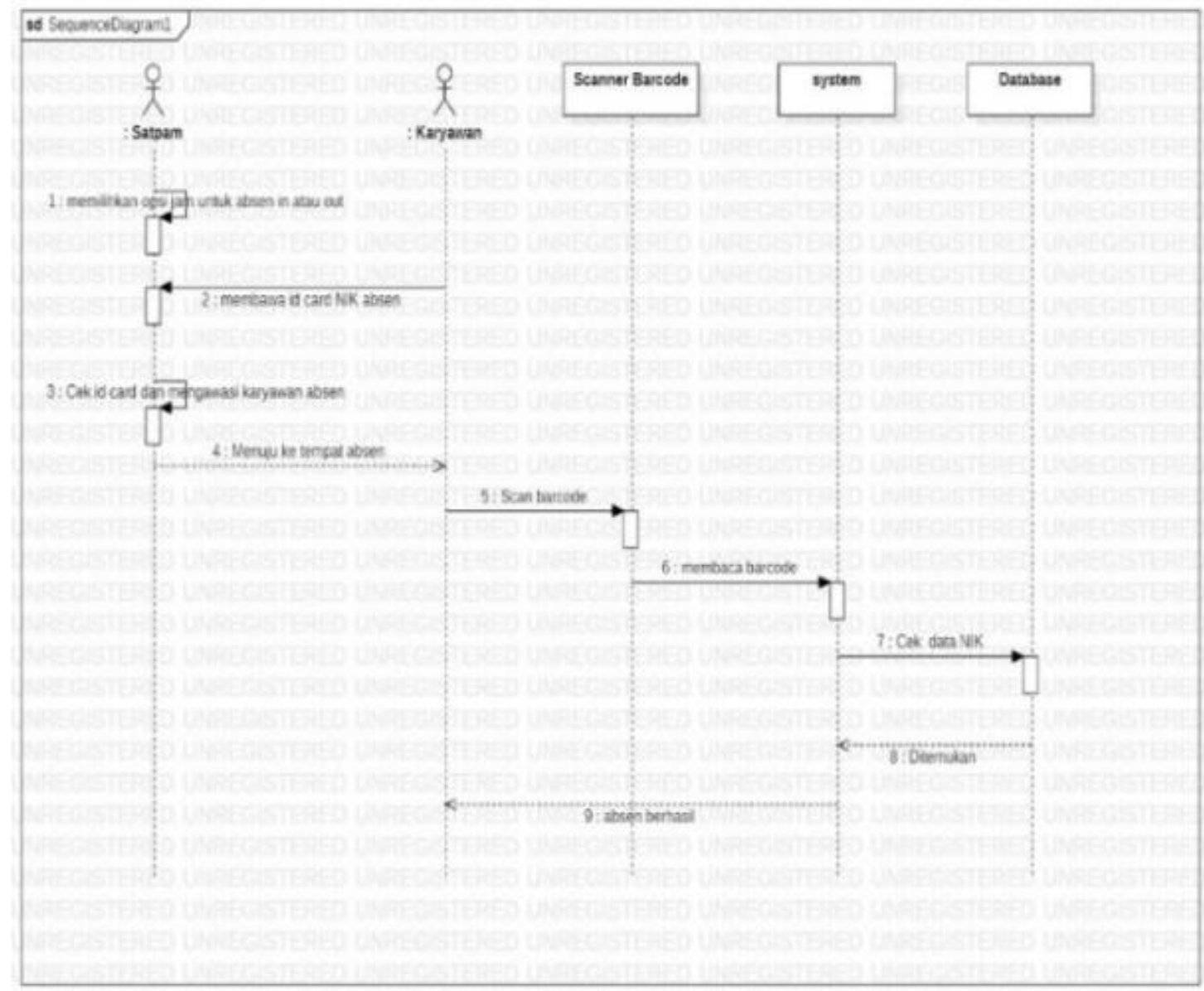

Gambar 4. Sequence Diagram Absensi In dan Out 


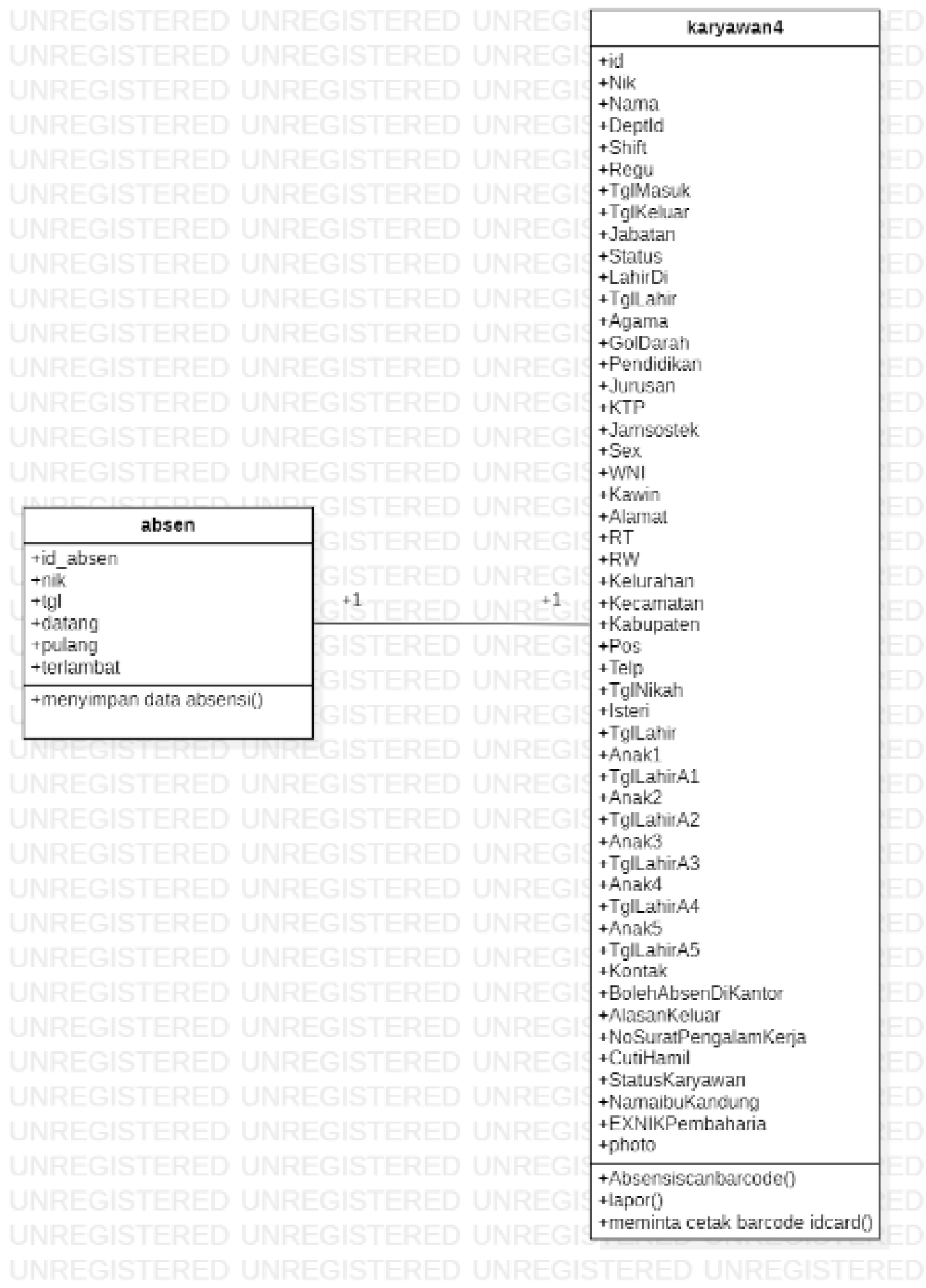

Gambar 5. Class Diagram 


\section{HASIL DAN PEMBAHASAN}

Dalam penelitian ini menghasilkan sistem absensi web menggunakan barcode yang dimana dalam penggunaanya dengan cara menscan barcode kartu ke scanner kemudian jika berhasil maka proses absensi sukses jika tidak maka akan muncul notifikasi untuk mengarahkan karyawan menemui bagian personalia untuk melakukan konfirmasi, dalam pembuatan ini sudah terdapat keamanan dimana karyawan tidak bisa melakukan absensi secara ketik manual sistem dibuat menggunakan bahasa pemrograman PHP, php adalah bahasa scripting yang diklarifikasi sebagai open source, php digunakan untuk mengembangkan perangkat lunak, php dapat diakses dengan mudah oleh pengembang [1], data yang berhasil untuk melakukan absensi akan tersimpan di database dengan menggunakan database mysql. Vue adalah kerangka kerja progresif untuk membangun pengguna antar muka, vue dirancang dari bawah hingga dapat digunakan secara bertahap dan vue juga mudah diambil dan diintegrasikan dengan yang lain [8]. Vue digunakan karena kemampuannya yang dapat membuat halaman menjadi reaktif [6].

Barcode adalah suatu data optik yang dibaca mesin, barcode mengumpulkan data dari lebar garis dan spasi garis paralel dan dapat disebut sebagai kode batang atau simbologi linier atau 1 dimensi. Selain dalam bentuk garis barcode juga memiliki bentuk persegi, titik, heksagon dan bentuk geometri lainnya di dalam gambar disebut kode matriks atau simbologi 2 dimensi. Selain tanda garis, sistem 2 dimensi sering disebut kode batang [5]. Barcode scanner menjadi solusi dalam pemecahan masalah pengelolaan data absensi dan memiliki keunggulan dapat melakukan pengambilan absensi dengan cepat, tepat dan akurat [2]. Berikut adalah kode program untuk tampilan utama absensi yang menggunakan vue js.

Kode program 1. Kode Program Untuk Tampilan Utama Absensi

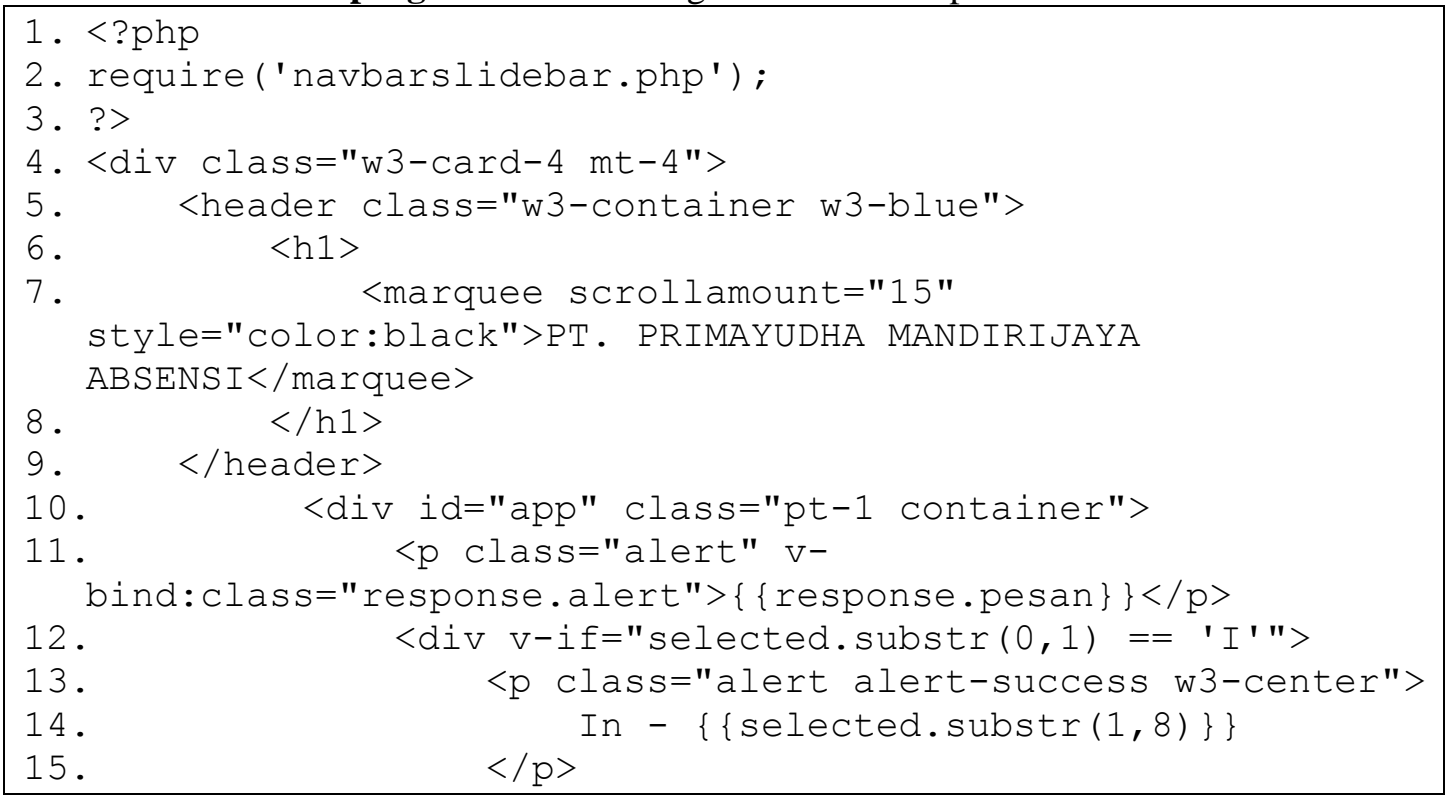

Kode program 1 merupakan penerapan view presensi dimana dalam pembuatannya menggunakan vue js framework. Bagian awal di kembangkan dengan kerangka vue js karena progresif yang ringan dan cepat mengandalkan model - view - view - model (MVVM) [11]. 
Kode Program 2. Kode Program Untuk Class Db Atau Database

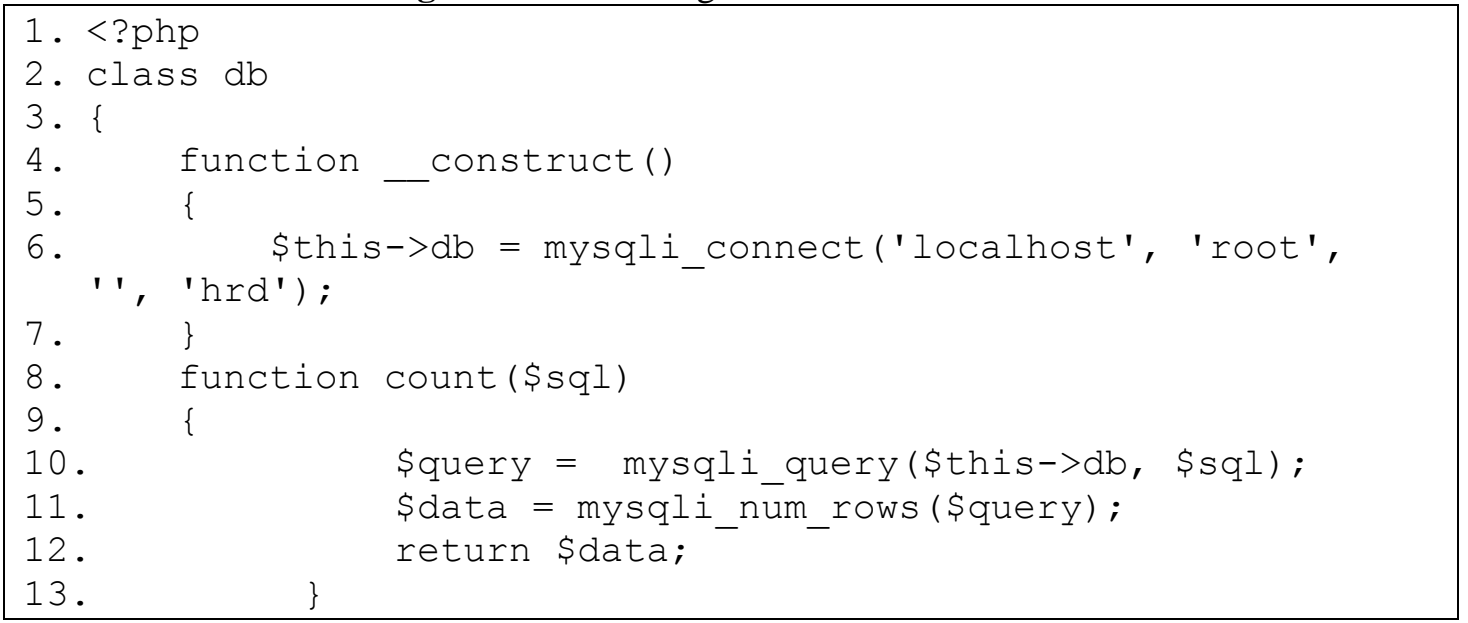

Kode program 2 merupakan penerapan dari db_controller dimana di dalam coding ini bertugas untuk mengkoneksikan dan mengatur data di database.

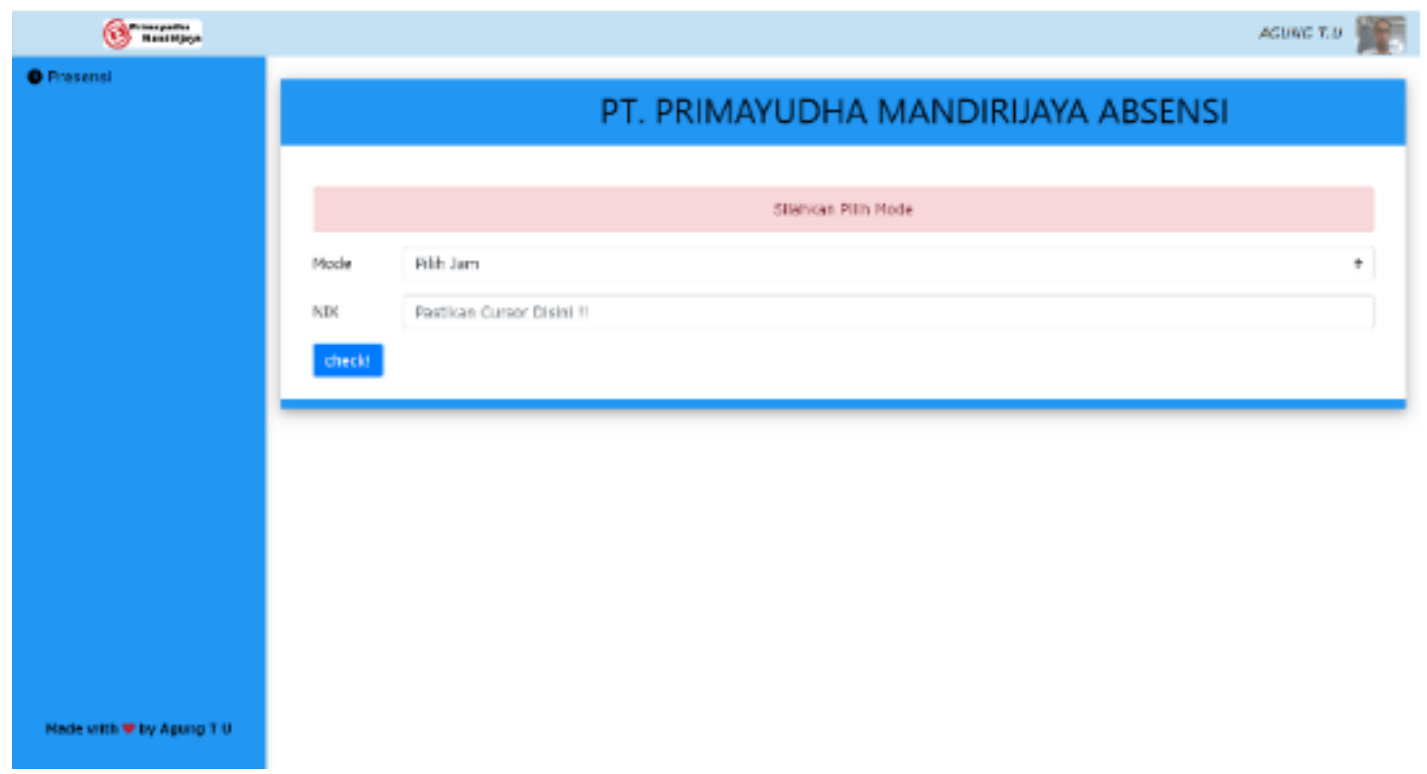

Gambar 6. Tampilan Absensi

Dalam penelitian ini menghasilkan sistem absensi web menggunakan metode barcode yang bisa mencatat absensi dengan cepat tepat dan akurat. 


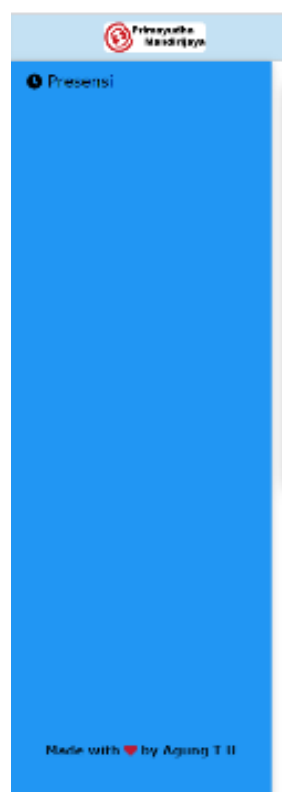

Aละบขอ 7.1

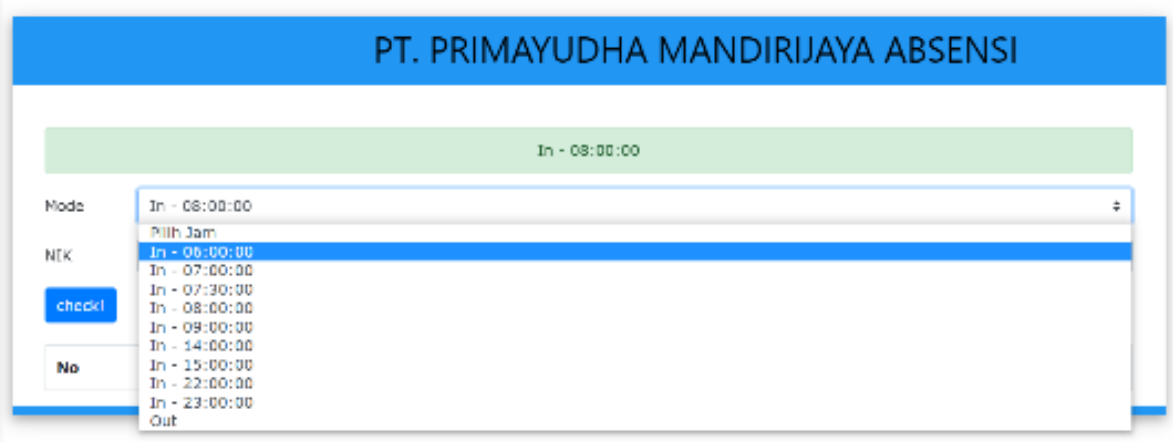

Gambar 7. Tampilan Absensi Mode Pilih Jam

Gambar 7 merupakan tampilan absensi dimana terdapat mode yang bisa memilih untuk menentukan pilihan jam IN dan out absensi.

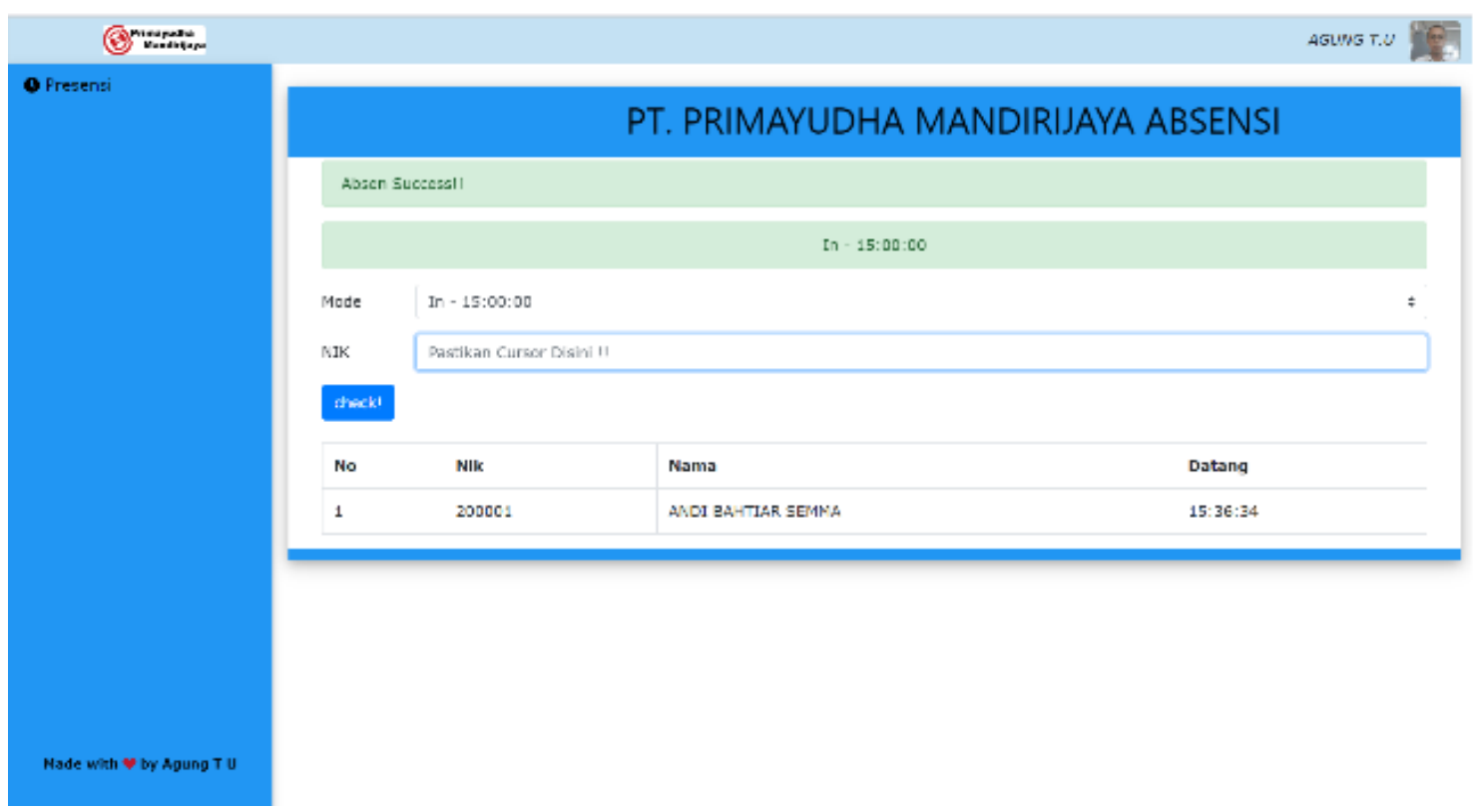

Gambar 8. Tampilan Absensi IN

Gambar 8 merupakan tampilan absensi datang, karyawan setelah melakukan scan barcode kemudian akan muncul pemberitahuan seperti "absen Success" apabila sudah terlihat pemberitahuan absensi sukses maka karyawan sudah siap untuk bekerja. 


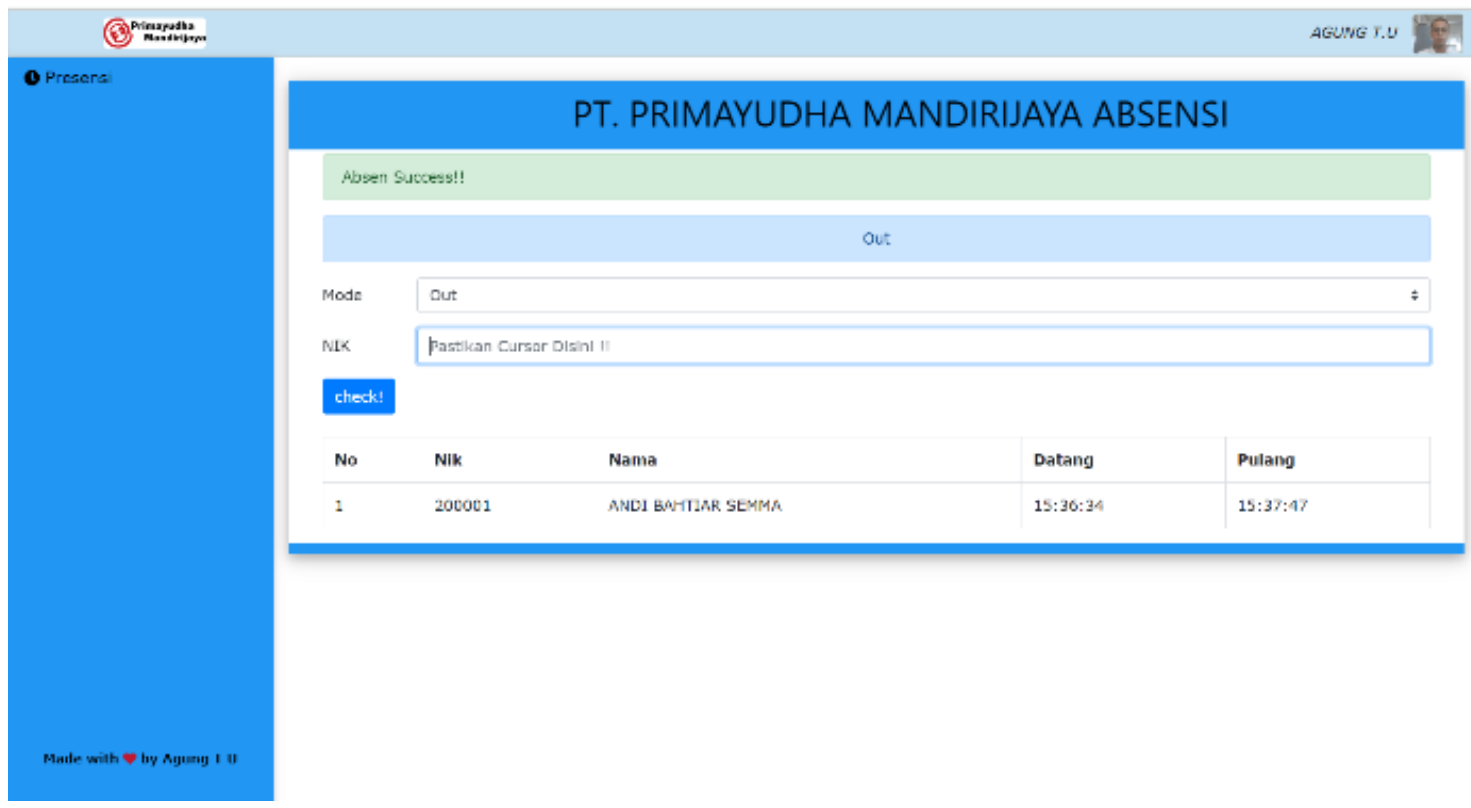

Gambar 9. Tampilan Absensi Out

Gambar 9 merupakan tampilan absensi pulang, karyawan setelah waktu bekerja selesai maka akan melakukan absensi out atau pulang dengan scan barcode apabila pemberitahuan absen sukses maka selanjutnya karyawan pulang.

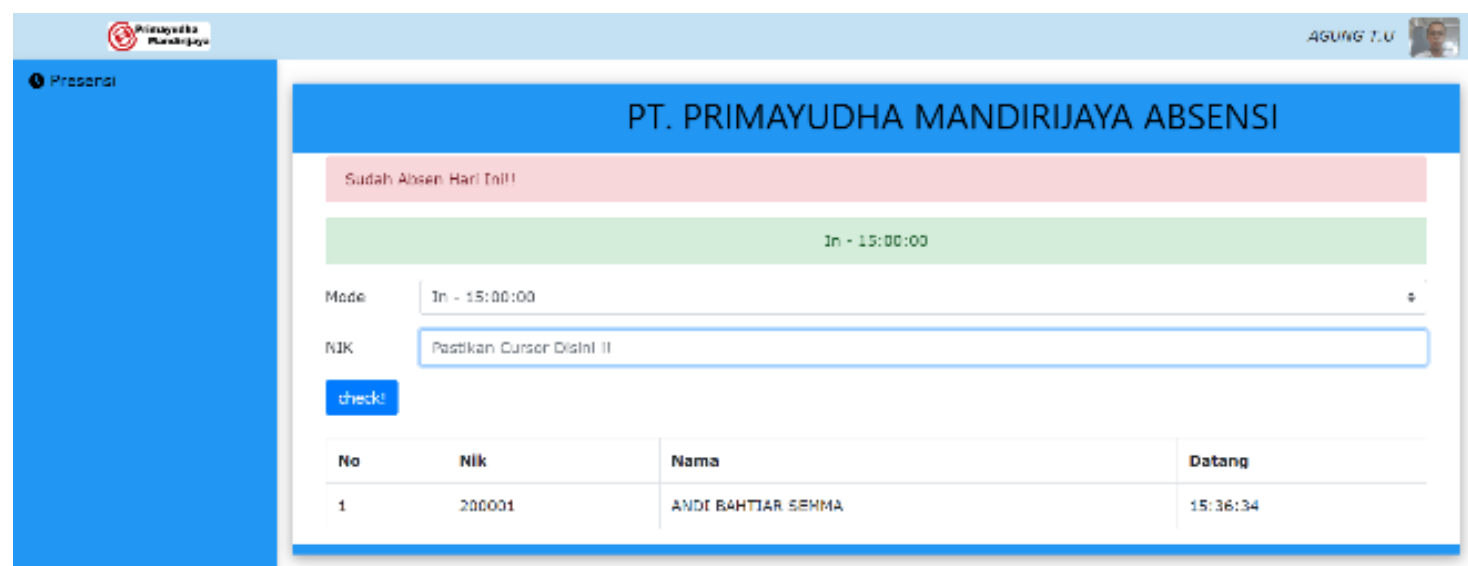

Gambar 10. Tampilan Absensi Sudah Absen Hari Ini

Gambar 10 pada tampilan absensi sudah absen hari ini, jika karyawan sudah melakukan absensi sekali maka dalam sistem tidak diizinkan lagi karyawan melakukan absensi lagi. 


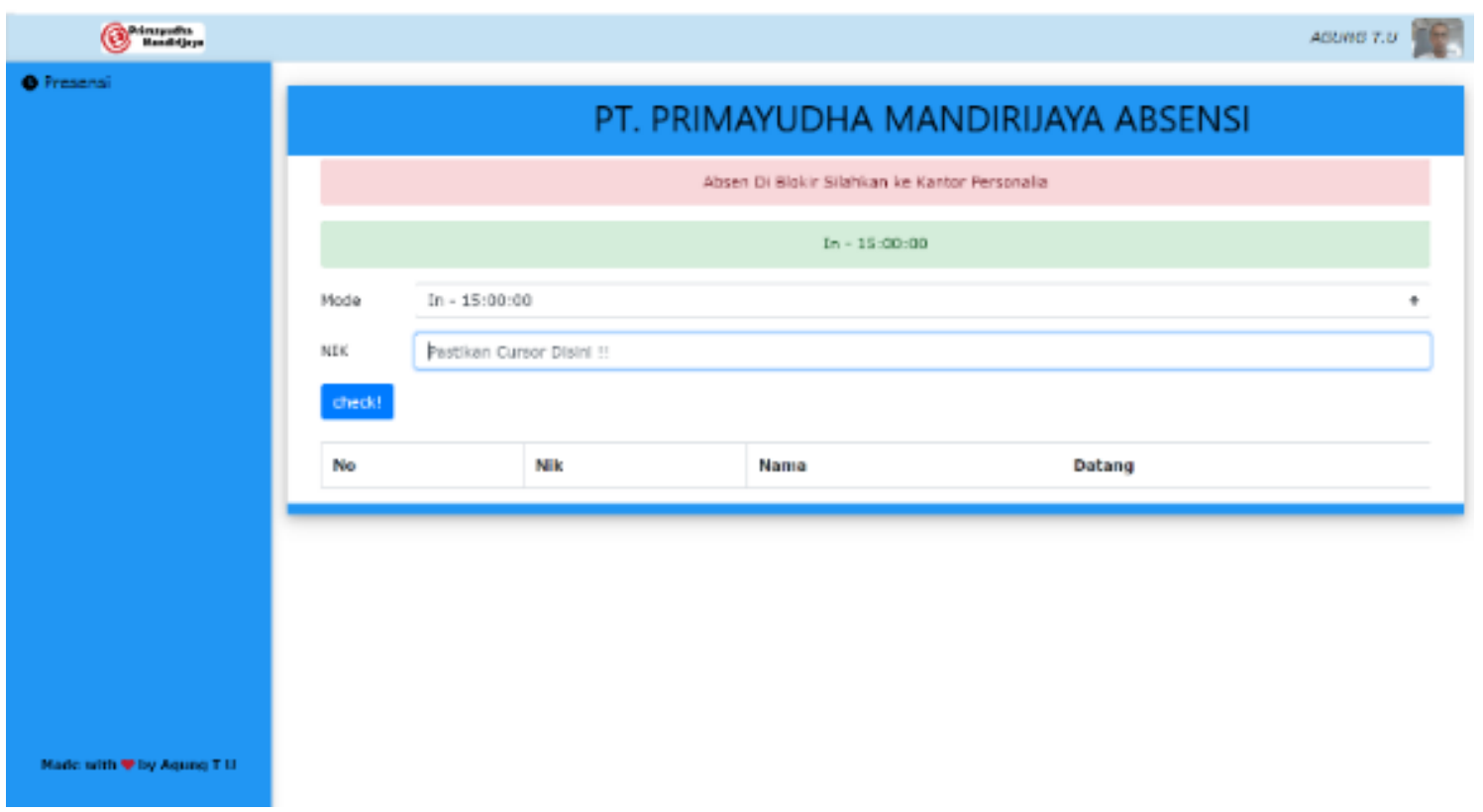

Gambar 11. Tampilan Absensi di Blokir

Gambar 11 dalam tampilan absensi di blokir ini bagi karyawan atau pihak yang tidak terdaftar pada sistem boleh absensi, maka tidak diperbolehkan untuk melakukan absensi berguna untuk mencegah pihak dari luar yang ingin merusak data.

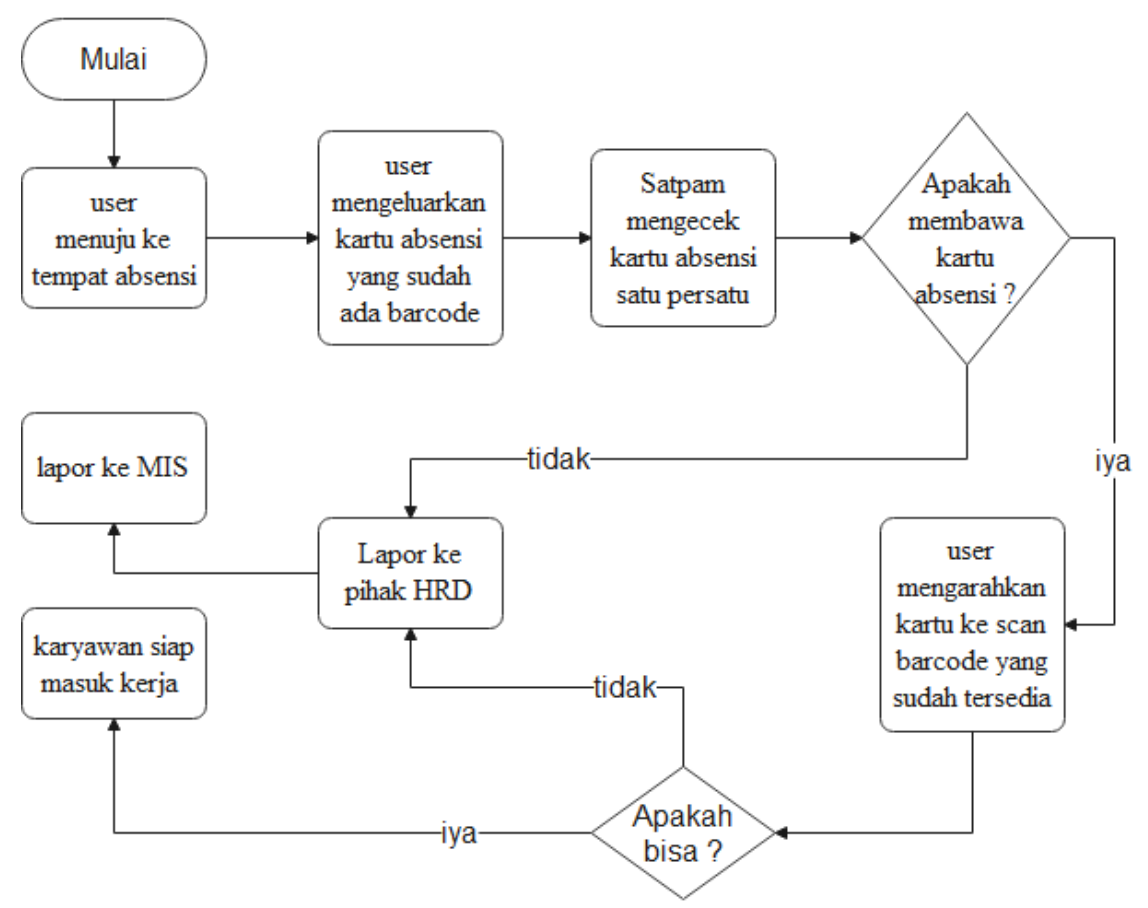

Gambar 12. Alur Penggunaan Absensi

Untuk yang tahap selanjutnya dengan menggunakan UAT (User Acceptance Test) dalam hal ini terdapat 6 pertanyaan, dapat di lihat di tabel 1. 
Tabel 1. Pertanyaan UAT

\begin{tabular}{ll}
\hline No & Pertanyaan \\
\hline 1 & Apakah sistem memberikan kemudahan? \\
2 & Apakah sistem bisa berjalan \\
3 & $\begin{array}{l}\text { Apakah dalam sistem absensi sudah di atur untuk tidak bisa } \\
\text { melakukan absensi dengan ketik manual? }\end{array}$ \\
4 & $\begin{array}{l}\text { Apakah absensi barcode bisa menjadi salah satu solusi yang } \\
\text { baik dalam protokol kesehatan selama pandemi covid-19 ini? }\end{array}$ \\
5 & $\begin{array}{l}\text { Apakah fungsi - fungsi sudah sesuai dengan yang diharapkan? } \\
6\end{array}$ \\
& Apakah tampilan absensi sudah menarik?
\end{tabular}

Berdasarkan tabel diatas kuesioner dilakukan dengan 10 orang karyawan staff, setelah penulis melihatkan baik itu gambar maupun sistem yang berjalan, maka selanjutnya melakukan perekapan hasil semua tanggapan sebagai berikut. Skala likert adalah skala yang digunakan untuk mengukur persepsi, sikap atau pendapat seseorang atau kelompok mengenai peristiwa atau fenomena sosial, berdasarkan definisi operasional yang ditetapkan oleh peneliti[3]. Perhitungan hasil kuesioner hasil dari semua tanggapan berdasarkan pertanyaan yang sudah di susun sebagai berikut.

Tabel 2. Bobot Nilai Skala Likert

\begin{tabular}{lc}
\hline Jawaban & Bobot Nilai \\
\hline Sangat Setuju & 5 \\
Setuju & 4 \\
Netral & 3 \\
Tidak Setuju & 2 \\
Sangat Tidak Setuju & 1 \\
\hline
\end{tabular}

Tabel 3. Total Nilai

\begin{tabular}{lll} 
Jumlah & Jawaban & Total Nilai \\
\hline 9 & Sangat Setuju & 45 \\
13 & Setuju & 52 \\
35 & Netral & 105 \\
3 & Tidak Setuju & 12 \\
0 & Sangat Tidak Setuju & 0 \\
& Total & $\mathbf{2 4 4}$ \\
\hline
\end{tabular}

Rumus : T x Pn

$\mathrm{T}=$ jumlah responden yang memilih

Pn $=$ Pilihan angka skor likert

Jadi hasil total nilai 244

$\mathrm{Y}=$ Skor tertinggi likert

$\mathrm{X}=$ Skor terendah likert

Penyelesaian akhir:

Rumus index $=$ Total skor $/ \mathrm{Y} \times 100$

$\mathrm{Y}=5 \times 10 \times 6$

$244 / 300 \times 100$ 
71,3\% berdasarkan dari hasil perhitungan dengan pengumpulan data diperoleh dengan kategori "Setuju".

Tabel 4. Kriteria Skor

\begin{tabular}{ll}
\hline \%Kepuasan & Keterangan \\
\hline $0 \%-19.99 \%$ & Sangat Tidak Setuju \\
$20 \%-39.99 \%$ & Tidak Setuju \\
$40 \%-59.99 \%$ & Cukup \\
$60 \%-79.99 \%$ & Setuju \\
$80 \%-100 \%$ & Sangat Setuju \\
\hline
\end{tabular}

\section{KESIMPULAN}

Sistem aplikasi absensi akan lebih memudahkan proses kontrol absensi In(datang), Out(pulang). sistem aplikasi absensi karyawan dengan web memanfaatkan barcode ini akan memberikan interface sistem dan penggunaannya yang user friendly. Sistem bisa mencatat absensi dengan cepat, tepat dan sudah terkoneksi masuk database. sistem absensi hanya bisa dilakukan dengan membaca barcode nik dan sistem sudah mengontrol dimana sistem tidak bisa diketik secara manual oleh user karena untuk menghindari orang yang tidak bertanggung jawab.

\section{SARAN}

1. Berharap adanya tambahan sistem untuk menyempurnakan seperti adanya penambahan sistem dimana dalam pemantauan absensi agar bisa otomatis bisa mengontrol user yang melakukan absensi.

2. Harap dilakukan maintenance data dengan cara mem back-up data agar data diamankan sehingga sistem dapat tetap berjalan dengan lancar.

3. Diharapkan tiap bagian dalam menyadari akan pentingnya keamanan data untuk menghindari penggunaan sistem oleh orang yang tidak bertanggung jawab.

\section{UCAPAN TERIMA KASIH}

Penulis mengucapkan terimakasih kepada Tuhan Yang Maha Esa, kedua orang tua dan saudara yang selalu mendukung dan menjadi pendorong saya dalam hidup, serta staff primayudha mandirijaya yang selalu mendukung saya dalam menjalankan proses pembuatan sistem, bapak Suprihadi, S.Si., M.kom selaku pembimbing tugas akhir yang selalu mengarahkan dan membantu dalam penulisan jurnal.

\section{DAFTAR PUSTAKA}

[1] Ahmad, D. K., Ahmad, M. F., Ahmad, M. N., \& Ahmad, A. S. 2020, An Experiment of Animation Development in Hypertext Preprocessor (PHP) and Hypertext Markup Language (HTML), International Journal of Scientific Research in Research Paper. Computer Science and Engineering, 8(2), 45-51. www.isroset.org 
[2] Ayu, F., \& Mustofa, A. 2019, Sistem Aplikasi Absensi Menggunakan Teknologi Barcode Scanner Berbasis Android, IT Journal Research and Development, 4(2). https://doi.org/10.25299/itjrd.2020.vol4(2).3642

[3] Choizes, E. 2017, Pengertian Skala Likert dan Contoh Cara Hitung Kuesionernya, Diedit.Com. https://www.diedit.com/skala-likert/

[4] Ismail, dan. 2020, Implementasi Sistem Informasi Absensi Guru Mengunakan Teknologi Fingerprint Di Sekolah Menengah Atas (SMA) Negeri 2, ScientiCO: Computer Science and Informatics Journal, 3(2). http://jurnal.untad.ac.id/jurnal/index.php/scientico/article/view/16355

[5] Jurnal, H., Saepulloh, A., \& Adeyadi, M. 2019, Jurnal Manajemen dan Teknik Informatika Aplikasi Scanner Berbasis Android Untuk Menampilkan Data ID Card Menggunakan Barcode, JUMANTAKA, 03(1), 1. http://jurnal.stmikdci.ac.id/index.php/jumantaka/article/view/418

[6] Ketut Aditya Herdinata Putra, I., Pramana, D., Luh Putri Srinadi, N., \& STIKOM Bali J1 Raya Puputan, S. 2019, Sistem Manajemen Arsip Menggunakan Framework Laravel dan Vue.Js (Studi Kasus: BPKAD Provinsi Bali), Jurnal Sistem dan Informatika (JSI), 13(2), 97-104. https://jsi.stikom-bali.ac.id/index.php/jsi/article/view/214

[7] Mayliana, N., \& Atmojo, W. T. 2019, Perancangan Sistem Informasi Absensi Karyawan Toko Berbasis Web (Studi Kasus pada PT. Borneo Raya Mandiri), Jurnal Inovasi Informartika, 4(2).

[8] Pšenák, P., \& Tibenský, M. 2020, The Usage of Vue JS Framework For Web Application Creation, Mesterséges Intelligencia, 2(2), 61-72. https://doi.org/10.35406/mi.2020.2.61

[9] Rio, N., DickyHariyanto, \& Sunita, E. 2019, Rancang Bangun Sistem Informasi Absensi Karyawan, PT.San Andreas Mandiri Bekasi, 5(2), 34-41.

[10] Siddiq Ahmad, P. 2020, Membangun Aplikasi Sistem Absensi Karyawan Dengan Barcode pada PT. Lambang Jaya, Onesismik, 4(1).

[11] Song, J., Zhang, M., \& Xie, H. 2019, Design and implementation of A Vue.js-Based College Teaching System, International Journal of Emerging Technologies in Learning, 14(13), 59-69. https://doi.org/10.3991/ijet.v14i13.10709

[12] Tristianto, C. 2018, Penggunaan Metode Waterfall Untuk Pengembangan Sistem Monitoring dan Evaluasi Pembangunan Pedesaan, In Jurnal Teknologi Informasi ESIT: Vol. XII (Issue 01). 